\section{Rachel Fletcher}

113 Division St.

Great Barrington, MA

01230 USA

rfletch@bcn.net

Keywords: Eero Saarinen, North Christian Church, descriptive geometry

\section{Research}

\section{Eero Saarinen's North Christian Church in Columbus, Indiana}

Abstract. Eero Saarinen's North Christian Church, an important contribution to post-war liturgical church architecture, serves a community of Disciples of Christ in Columbus, Indiana. Early design sketches illustrate elementary geometric shapes and symbols - triangle, square, cross, hexagon, and octagon - whose proportions appear in the plan and section of the completed structure.

\title{
Introduction
}

...they should feel they are all in unity and harmony in a special and appropriate spiritual atmosphere.

Eero Saarinen, on North Christian Church (1960) [Saarinen 1962: 88]

An important contribution to postwar liturgical church architecture, Eero Saarinen's North Christian Church serves a northern residential suburb of Columbus, Indiana. Designed between 1959 and 1961 and completed in 1964, the central plan church accommodates greater participation and more intimate and democratic congregational involvement.

Saarinen desired a simple structure that would support the liturgical needs of its members and "clearly and logically express the form and character of the church" (on North Christian Church (1960) [Saarinen 1962: 88]). Its open structure, facilitated by new advances in steel construction, dissolves the traditional distinction between officiate and congregant, while recognizing communion and baptism as important liturgical sacraments.

\section{Exterior}

Saarinen designed the church at the request of J. Irwin Miller, following the architect's design for Miller's private residence (1953-57). ${ }^{2}$ In 1955, forty-three members of First Christian Church broke away to organize a more liberal institution affiliated with the Disciples of Christ. In 1958, with Miller's assistance, the group purchased a five and a half acre tract of land and met in various locations until Saarinen's church was completed. $^{3}$

The whole thing, all the planes, would grow up organically into the spire - on North Christian Church (1960) [Saarinen 1962: 90]

The main level of the two story structure rests on a massive concrete base. The lower level nestles into a landscaped berm held back to expose a moat-like light well. The building is hexagonal in plan, elongated on the east-west axis. Six steel legs clad in leadcoated copper secure a pyramidal slate roof, then converge at an apex, rise to a tapered 192-foot central spire and terminate at a five-foot gold-leaf cross (fig. 1) [Knight 2008: 163; Thayer 1999: 4]. 


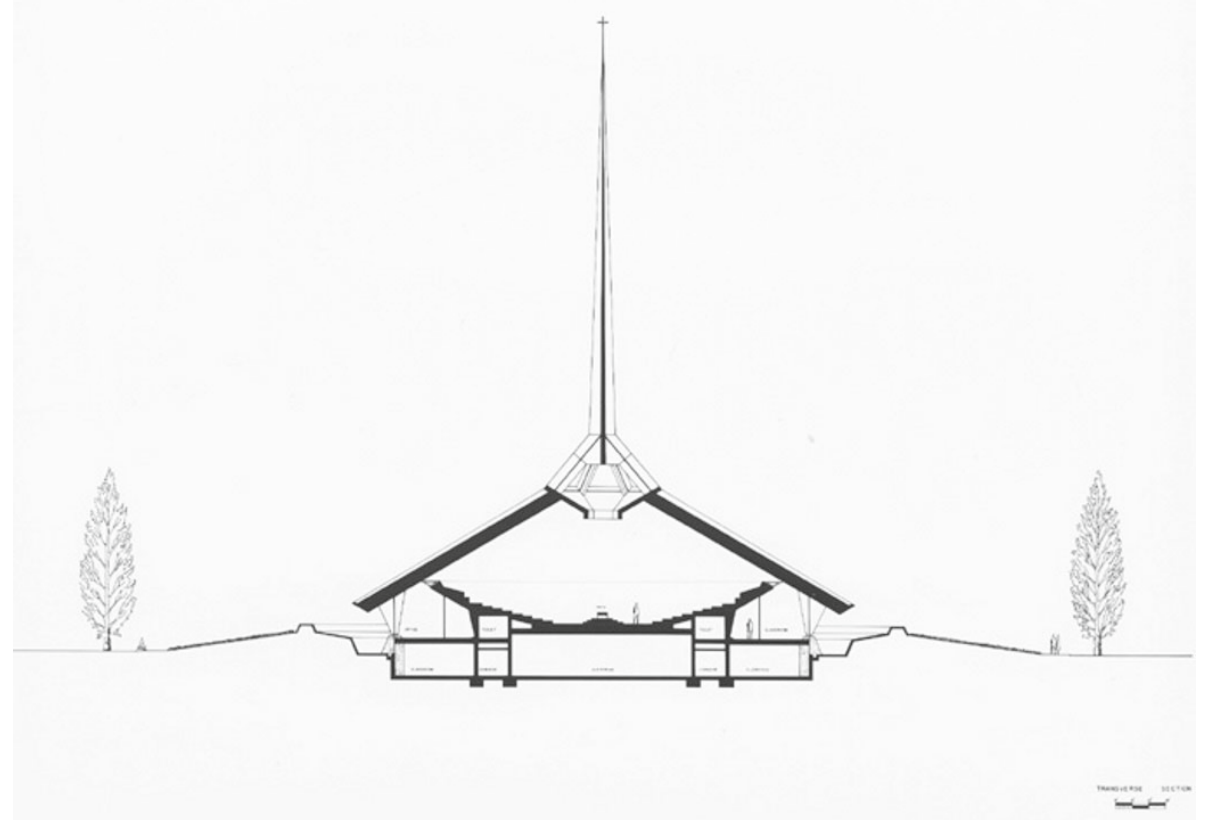

Fig. 1. North Christian Church, Columbus, Indiana. Transverse section. Image: Eero Saarinen, Collection Manuscripts \& Archives, Yale University

(Image No. 9733)

...put only the sanctuary above ground and make it the significant visual and architectural thing.

- on North Christian Church (1960) [Saarinen 1962: 88]

Only the main sanctuary and a small baptismal chapel, both surrounded by an ambulatory, remain above ground. Support facilities consolidate within a single unit hollowed out in the basement below. The surrounding six-foot high berm conceals from view everything but the roof and entrance. The result is a simple and distinctly singular structure that appears to hover lightly above the ground, an illusion enhanced by recessed exterior glass walls set back some twelve feet from the roof s edge [Thayer 1999: 4].

\section{Interior}

...you should have to work for it and it should be a special thing.

- on North Christian Church (1960) [Saarinen 1962: 88]

Acts of entry and passage simulate a spiritual journey to another world. From the parking area, one ascends, and then descends before reaching the building at ground level. Once inside, steeper steps lead to the sanctuary.

...communion is a very important act and the congregation participates in it. - on North Christian Church (1960) [Saarinen 1962: 88]

Each building level follows the same hexagonal plan. Above, the main east entrance leads through a spacious vestibule to a large bowl-shaped sanctuary placed at the center and elevated to emphasize its liturgical importance. At the very center, beneath an oculus and raised on a dais, a communion table, containing twelve places arranged in two rows 
with a taller place at one end, represents Christ and His twelve disciples. The dais can be rotated and repositioned on other occasions.

...everyone feels equal and joined together.

- on North Christian Church (1960) [Saarinen 1962: 88]

Surrounding the communion table on five sides, mahogany benches bring congregants close to the service. Organ, choir benches and pulpit complete the round on the sixth side.

...immersion should be given more dignity... viewed only by family and close friends.

- on North Christian Church (1960) [Saarinen 1962: 90]

Free-standing walls on diagonal axes frame a secondary baptistery chapel at the west end, where immersion baptism is performed in a small hexagonal pool of white tile set into the floor. Seating faces inward toward the center. On other occasions, the pool is covered.

...put all that activity downstairs. Maybe underground, hidden away...

- on North Christian Church (1960) [Saarinen 1962: 88]

Underground perimeter classrooms, offices and other support facilities face the berm, lit by ambulatory windows at the base of the church. In the center, an auditorium is placed directly below the sanctuary.

\section{The primary element to create the right spiritual atmosphere would, of course, be light. \\ - on North Christian Church (1960) [Saarinen 1962: 90]}

Theatrical light sources lend mystery to the sanctuary experience. A hexagonal skylight at the base of the spire focuses natural light on the communion table, an effect augmented by recessed can lights in the ceiling nearby. Along the sanctuary's perimeter, indirect natural light from ambulatory windows reflects angled ceiling surfaces, causing the roof to appear to float [Merkel 2005: 160; Thayer 1999: 5; Miller 2006: 65].

\section{Geometric symbolism}

...the total concept is carried down to the smallest detail.

- On Interior Design (1960) [Saarinen 1962: 11]

More than decoration or ornament, abstract geometric symbols convey spiritual experience and meaning. Hexagonal figures represent the Star of David, or Magen David, recognized universally as the symbol of Judaism (cf. [Fletcher 2005: 142-145]). The spire represents for the architect "a marvelous symbol of reaching upward to God," commanding the landscape in its function as axis mundi. The cross at its apex represents Christianity's emergence from Judaic origins through Christ's sacrifice [Miller 2006: 65]. Early design sketches contain a variety of elementary geometric shapes and symbolstriangle, cross, square, hexagon and octagon - that contribute to the finished church plan and section (fig. 2). 


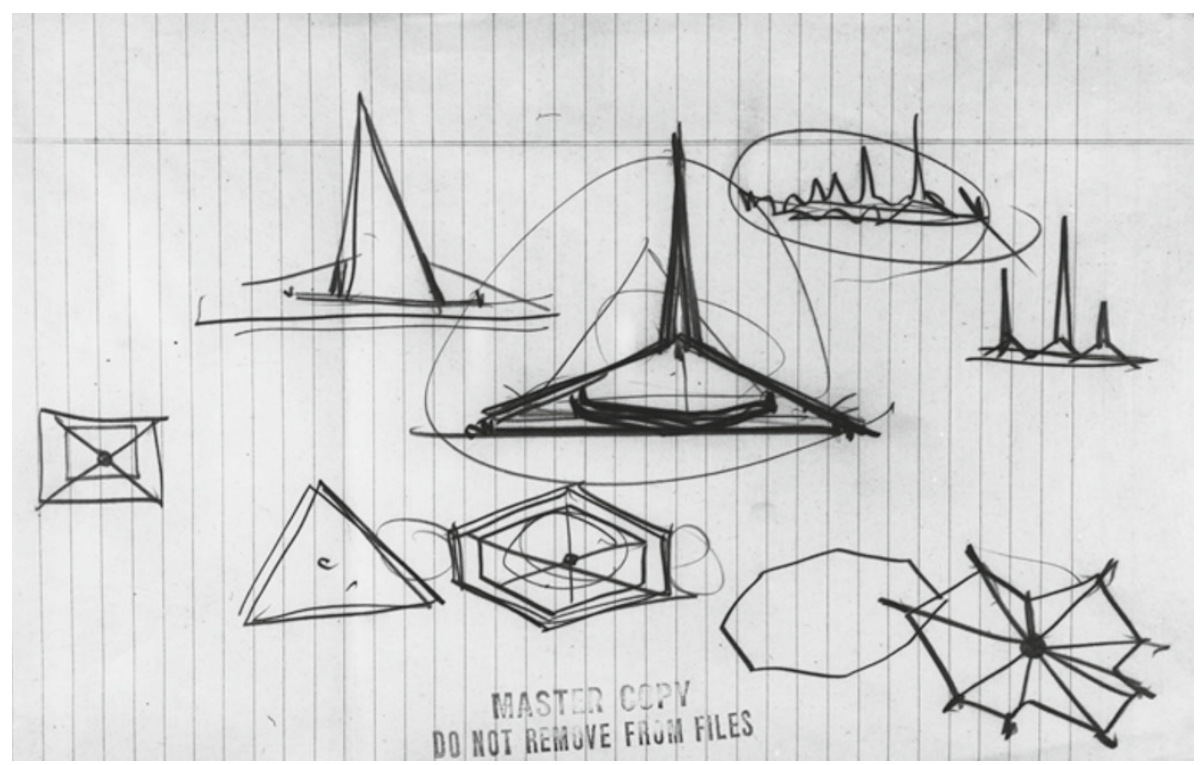

Fig. 2. North Christian Church, Columbus, Indiana. Sketches. Eero Saarinen,

Collection Manuscripts \& Archives, Yale University (Image No. 9736)

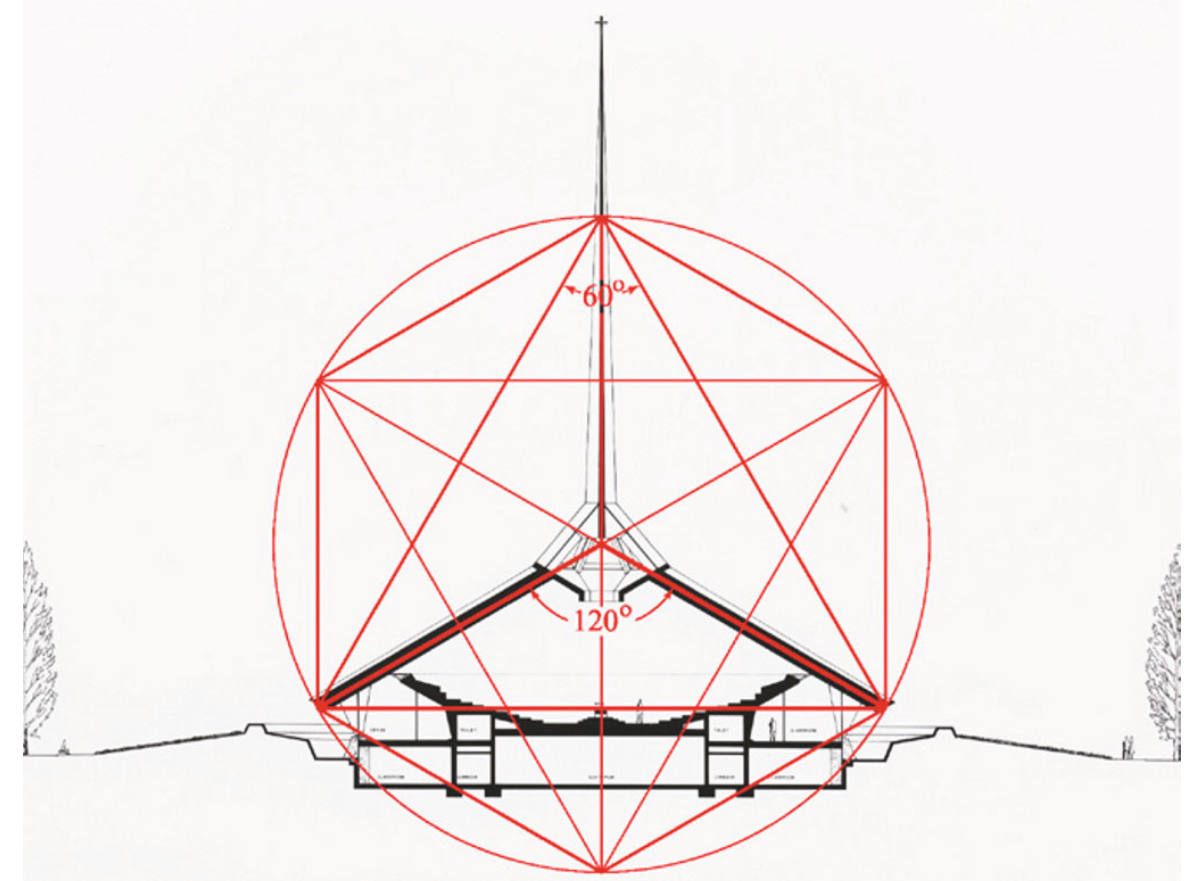

Fig. 3. North Christian Church. Transverse section with geometric overlay. Base image as in fig. 1; geometric overlay: Rachel Fletcher 


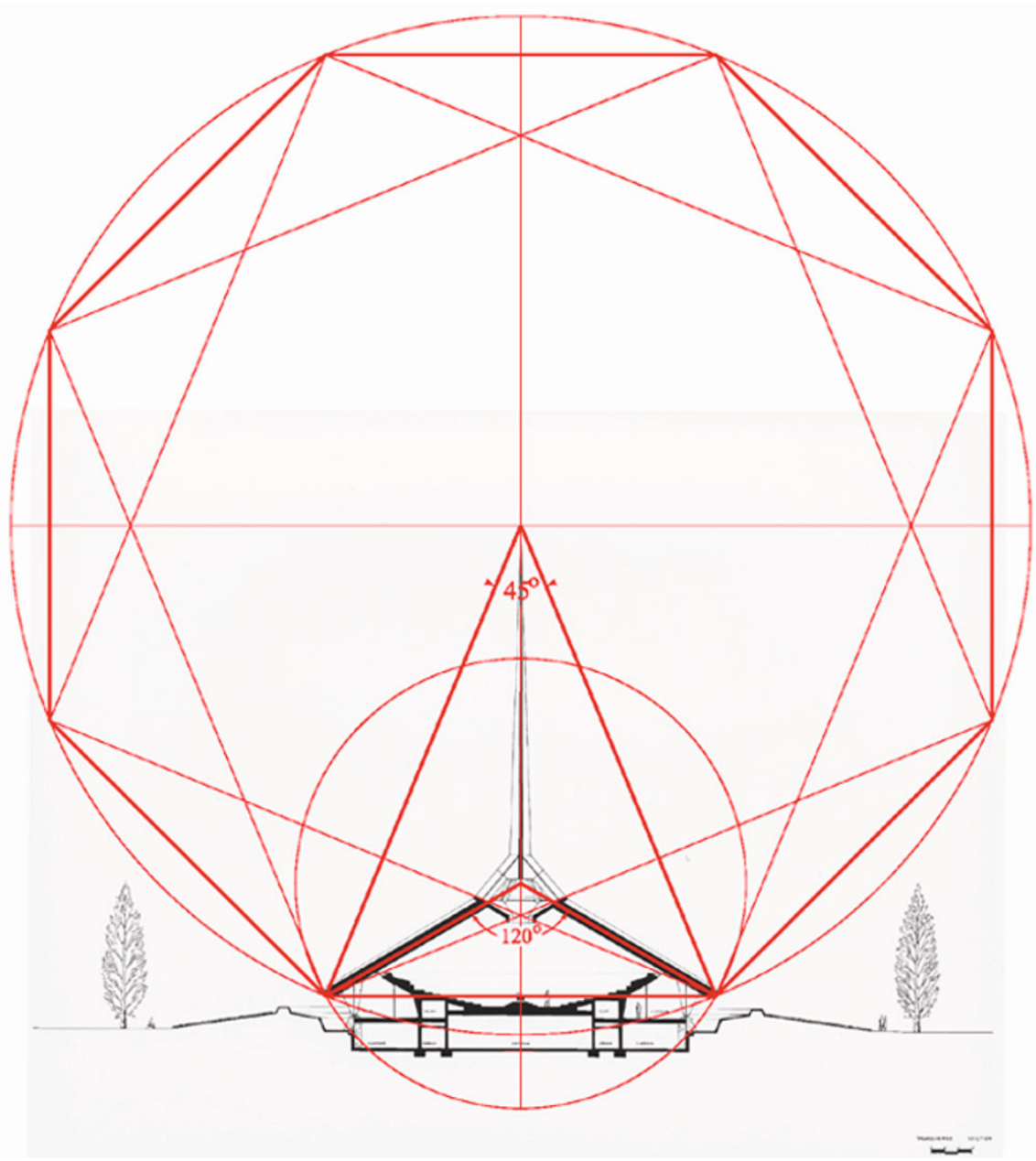

Fig. 4. North Christian Church. Transverse section with geometric overlay. Base image as in fig. 1; geometric overlay: Rachel Fletcher

\section{Geometric analysis}

\section{Section}

In section, the spire and roof converge along three equally spaced axes. In fig. 3, a regular hexagon, hexagram (or Star of David), and equilateral triangle are drawn on these axes. Roof lines coincide with two equal sides of a $120^{\circ}$ isosceles triangle.

In fig. 4, a $45^{\circ}$ isosceles triangle is drawn on the same base as the $120^{\circ}$ isosceles triangle. Its apex coincides with the gold-leaf cross at the top of the spire. From the apex is drawn a circle, as shown, that encloses a regular octagon and an eight-faceted figure composed of two squares. The two squares intersect along the plane of the oculus. 
The main level of the church features an elongated hexagon that encompasses bermframed moats on the long sides, north and south, and stepped concrete approaches on the short sides, east and west. Just beyond, parallel diagonal lines delineate landscape features and trees. Inside, concentric hexagons locate the building proper and sanctuary floor (fig. 5).

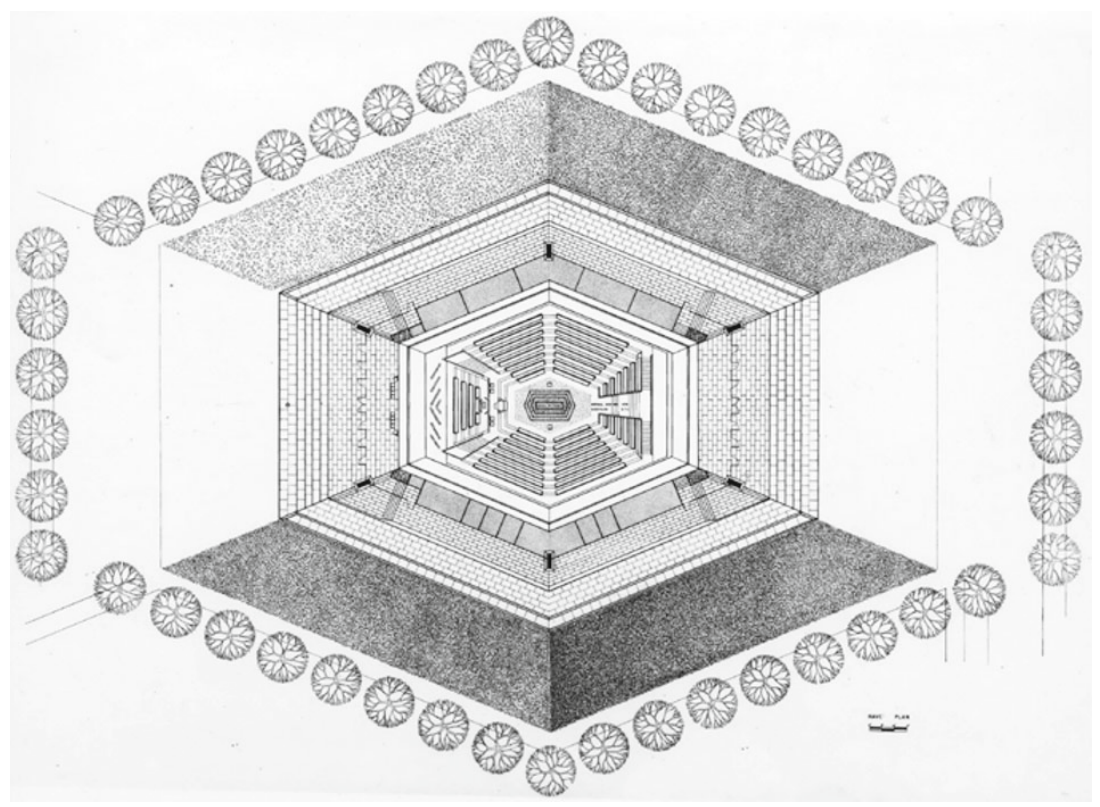

Fig. 5. North Christian Church, Columbus, Indiana. Plan of main level. Image:

Courtesy Cranbrook Archives, Maurice Allen papers. Also Eero Saarinen,

Collection Manuscripts \& Archives, Yale University (Image No. 9734)

Forty-five degree isosceles triangles locate the short sides of the hexagon on the east and west (fig. 6).

Three axes, as shown, situate the extent of the hexagon and suggest the threedimensional frame of the cube (fig. 7).

The outer hexagonal footprint derives from the root-two proportions of a regular octagon and an inscribed eight-faceted figure composed of two squares. The hexagon's short east-west sides coincide with two edges of the octagon. Its long north-south sides are equal in length to the radius of the octagon's circumscribing circle and follow the edges of the squares (fig. 8).

Saarinen's early sketches include squares and octagonal figures of a similar nature (fig. 9). 


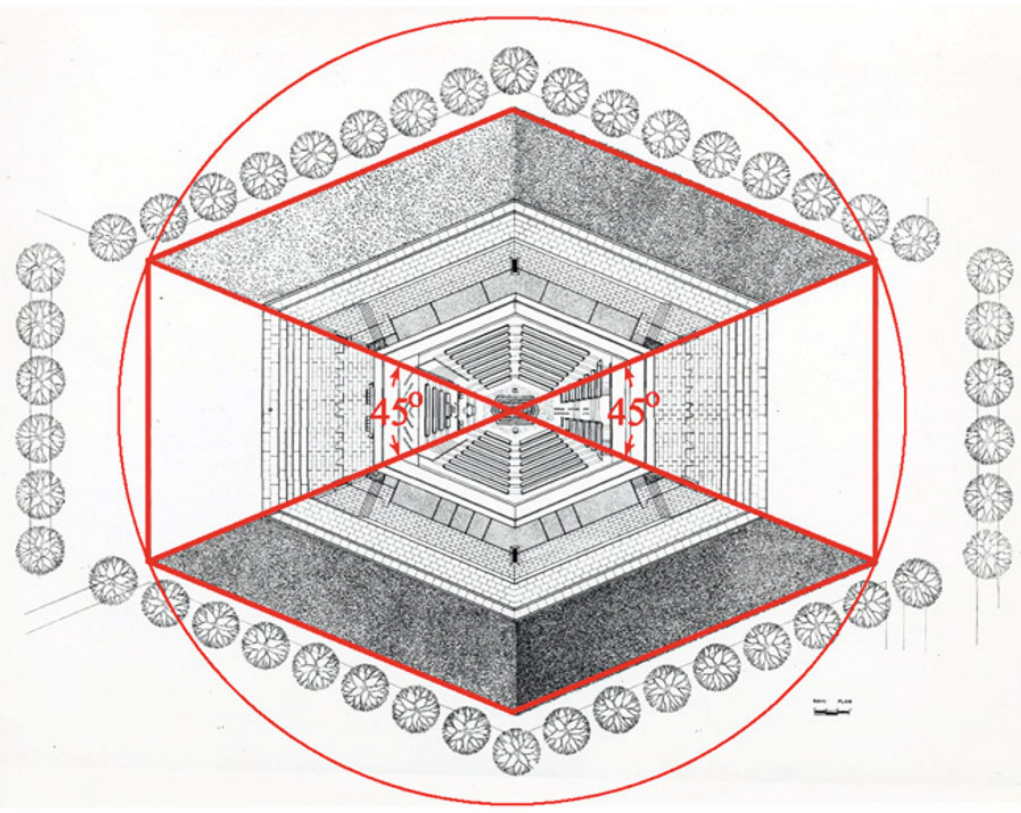

Fig. 6. North Christian Church. Plan of main level with geometric overlay. Base image as in fig. 5; geometric overlay: Rachel Fletcher

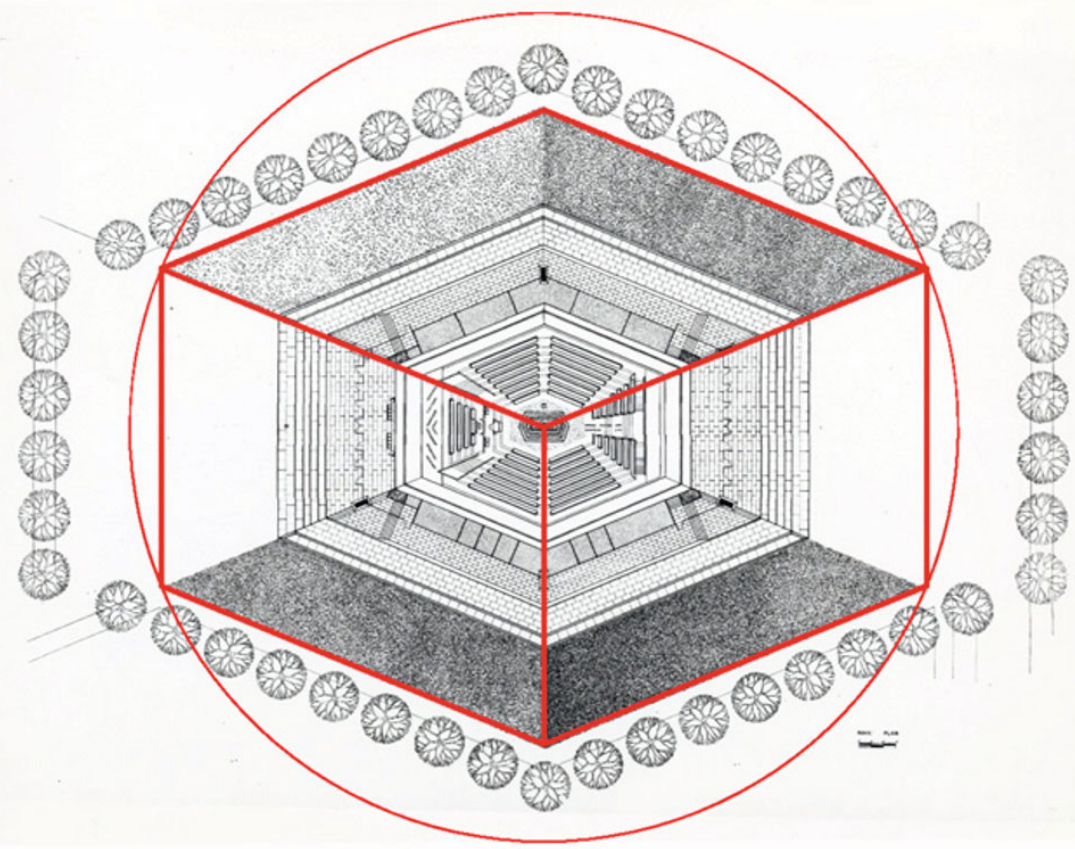

Fig. 7. North Christian Church. Plan of main level with geometric overlay. Base image as in fig. 5; geometric overlay: Rachel Fletcher 


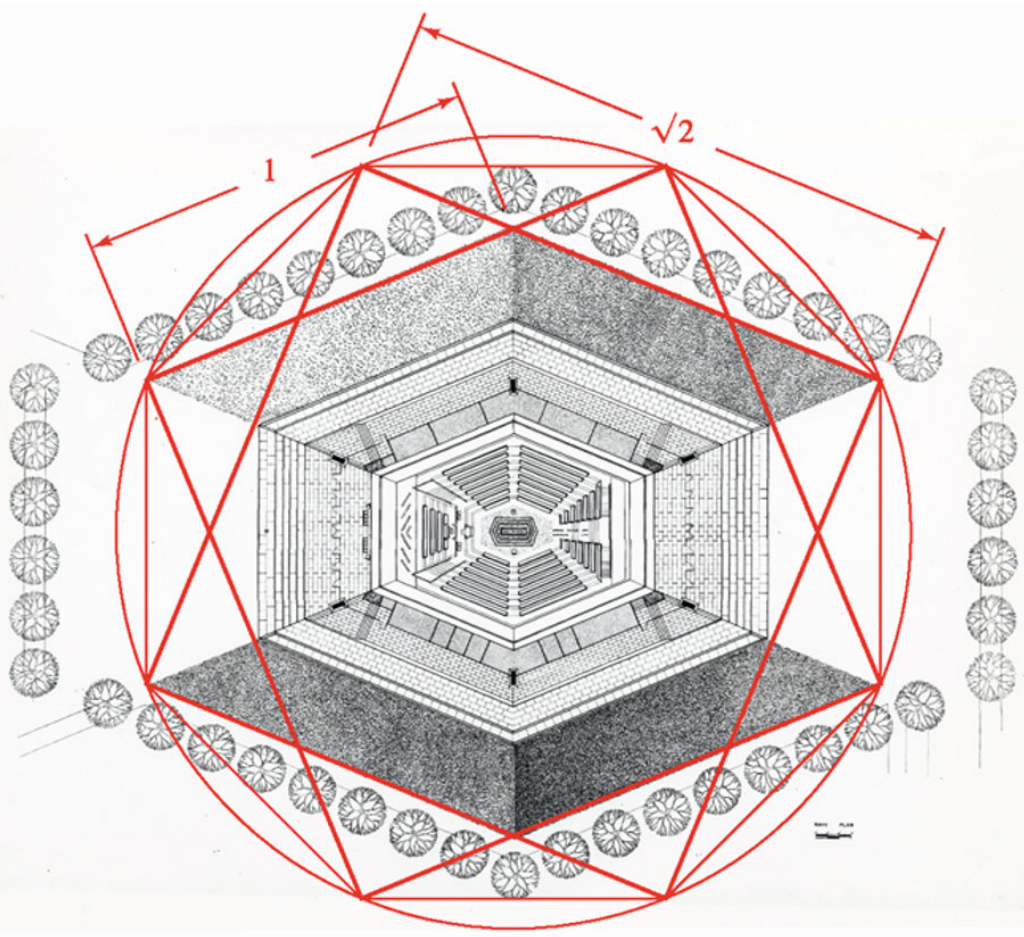

Fig. 8. North Christian Church. Plan of main level with geometric overlay. Base image as in fig. 5; geometric overlay: Rachel Fletcher

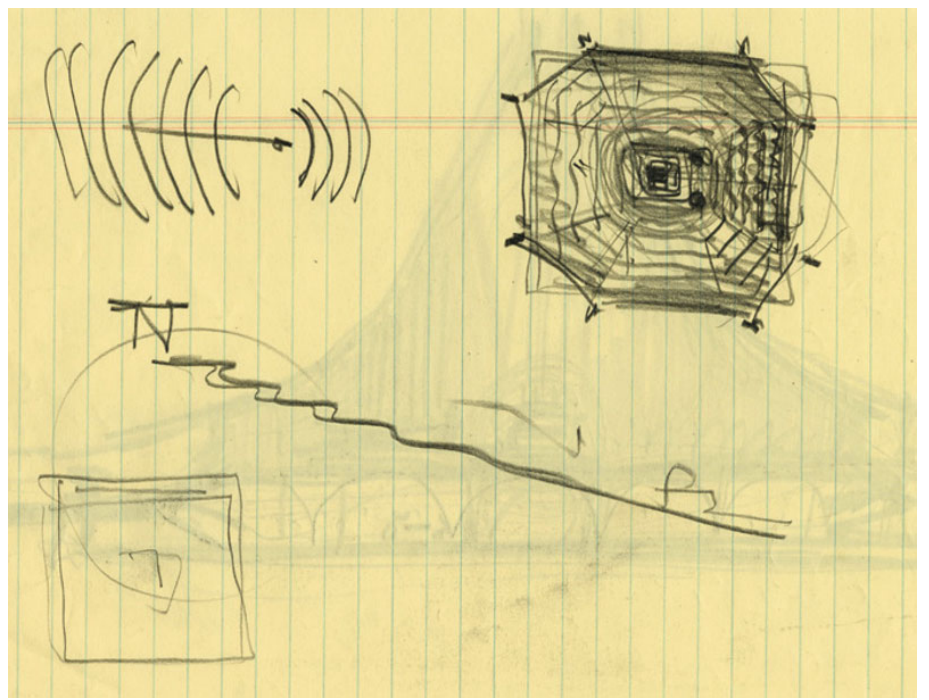

Fig. 9. Sketches of North Xian Church, 1950s / Eero Saarinen, artist, graphite; 20 x $32 \mathrm{~cm}$. Courtesy of the Aline and Eero Saarinen papers, 1906-1977, Archives of American Art, Smithsonian Institution 
- On Relationships in Design (1958) [Saarinen 1962: 11]

Within the plan, the outline of the building proper repeats and relates proportionally to the outer hexagonal footprint. Its shape follows a smaller, eight-faceted figure whose circumscribing circle inscribes the original eight-faceted figure (fig. 10).

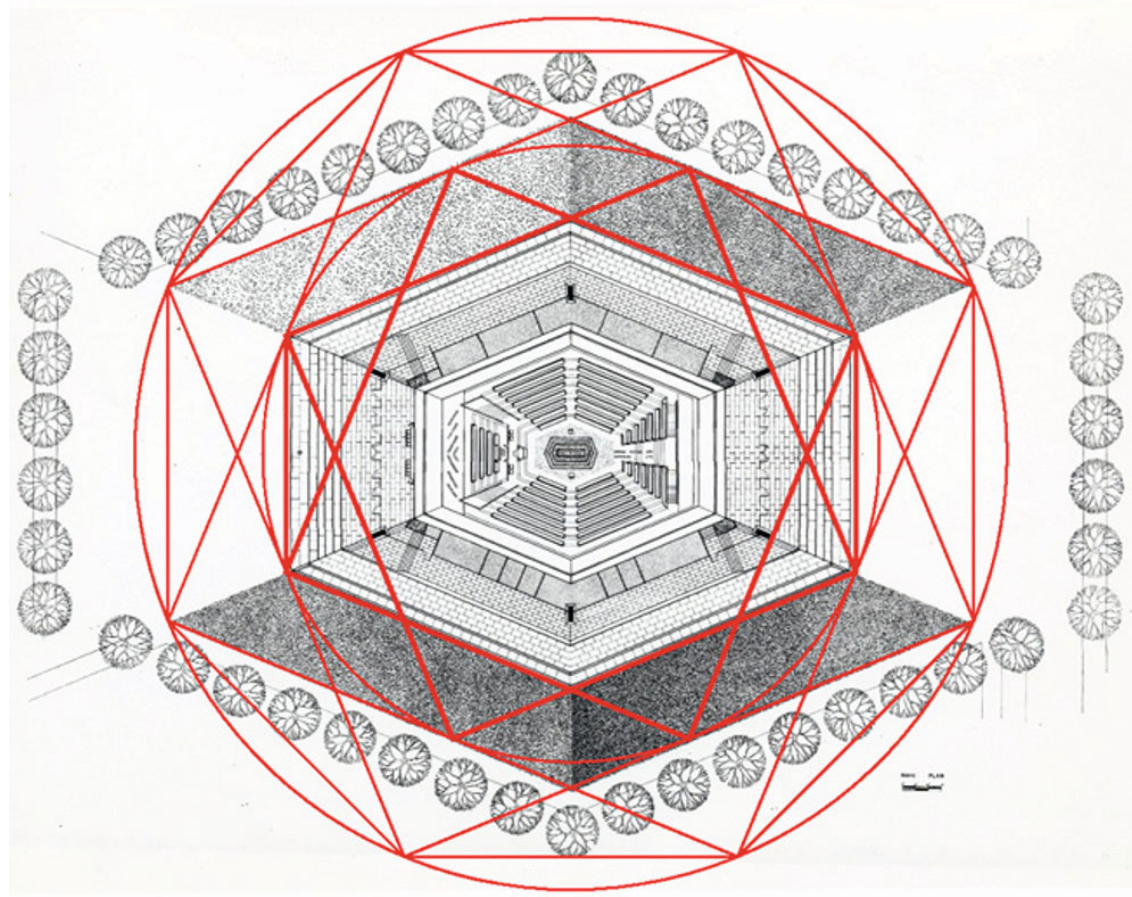

Fig. 10. North Christian Church. Plan of main level with geometric overlay. Base image as in fig. 5; geometric overlay: Rachel Fletcher

\section{Landscape}

... a building grows from its site...

- On Architecture (1959) [Saarinen 1962: 6]

Saarinen's partnership with Dan Kiley, a leading landscape architect of the modern era, ensured a seamless integration of building and setting. Kiley proposed to transform the flat treeless lot by surrounding the church with dense groupings of trees. A plot plan published in Architectural Record projects the building's proportions beyond the walls of the church (cf. [Saarinen's Church 1964: 187]).

The landscape plan for North Christian Church developed over several years and never materialized fully. But thickets of magnolia trees were planted along the north and south, and dwarf crabapple trees at the east and west entrances [Olivarez 2006: 274; Thayer 1999: 6, 10]. In Saarinen's early sketches, geometric lines and proportions extend beyond the church structure (cf. [Aline and Eero Saarinen Papers 1906-1977, (Image No. 5) AAA_saaralin_284659]). In the finished plan, geometric lines that delineate 
landscape features on the north and south parallel the long sides of the hexagonal footprint and are tangent to the circle that passes through the points of intersection of the two major squares (fig. 11).

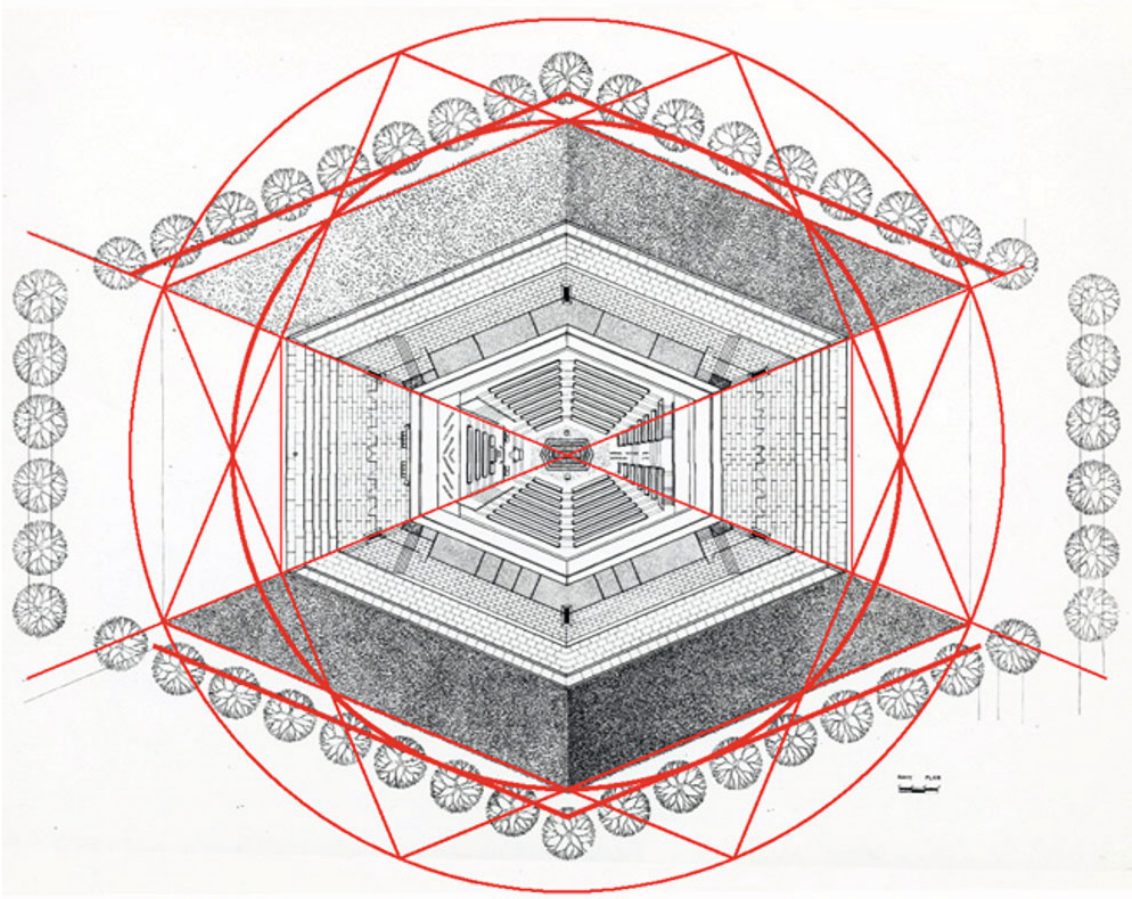

Fig. 11. North Christian Church. Plan of main level with geometric overlay. Base image as in fig. 5; geometric overlay: Rachel Fletcher

\section{Saarinen's last building}

Solving the total design of North Christian Church did not come easily to Saarinen and after two years the client grew impatient with the length of his process. ${ }^{4}$ In April 1961, the architect responded:

We have finally to solve this church so that it can become a great building...so that as an architect when I face St. Peter I am able to say that out of the buildings I did during my lifetime, one of the best was this little church, because it has in it a real spirit that speaks forth to all Christians as a witness to their faith [Saarinen 1962: 90].

In July 1961 Saarinen wrote that "we have finally solved the Columbus church" [Saarinen 1962: 90]. Weeks later, shortly after being diagnosed with a brain tumor, he died on the first of September. 


\title{
Conclusion
}

\author{
...organic unity is the ideal. \\ - On Interior Design (1960) [Saarinen 1962: 11]
}

It is not certain that Saarinen composed the spaces of North Christian Church by adopting these proportions and techniques. Nor do we know if he merged hexagon and square to symbolize the Star of David united with the Cross.

Saarinen recognized the merits of geometric proportion, but in unpublished notes warned against adopting a singe canon or allowing one's sense of proportion to "to be frozen by rules and regulations" or confined to "divine and indisputable laws." Good design, he maintained, is an "integrated package" that incorporates "space, use, structure, material, texture, proportions, and last but not least, the spirit of our time" (Saarinen, "Golden Proportions," unpublished notes for a lecture, 1953 [Pelkonen 2006: 342343]). Intuition, he proposed, is the best vehicle for capturing the total picture, more than any single element.

Intuition can be nurtured by a working knowledge of proportional techniques. These should serve a program's spiritual, social and functional requirements, and respond appropriately and organically to the situation at hand. The sublime beauty of North Christian Church demonstrates this ethic to perfection.

\section{Notes}

1. According to Jennifer Komar Olivarez, the liturgical revival begun in late nineteenth century Europe evolved through the influences of the 1938 treatise The Church Incarnate by German architect Rudolf Schwarz; postwar modern churches of Schwarz and German contemporary Dominikus Böhm; the 1947 German Liturgical Commission, and in the Catholic Church, Second Vatican (Vatican II) reforms adopted in 1965 [Olivarez 2006: 267-268]; see also [Ray 2005: 3].

2. Miller represented the new church, acting as chair of the search committee that selected the architect among several nationally known candidates.

3. [Knight 2008: 45; Merkel 2005: 158-159]. Architect Eliel Saarinen, Eero's father, designed First Christian Church (1939) in collaboration with his son. The National Historic Landmark Nomination locates North Christian Church near the west end of a 13.5 acre property [Thayer 1999: 4].

4. By late January 1961, Saarinen had neither resolved the lantern nor related the interior and exterior to his satisfaction [Saarinen 1962: 90].

\section{References}

Aline and Eero Saarinen Papers, 1906-1977. Archives of American Art, Smithsonian Institution.

Box 2 Folder 3 Sketches of North Xian Church, Eero Saarinen 1950s. http://www.aaa.si.edu/collectionsonline/saaralin/container37465.htm

Eero Saarinen Collection. 1880-2004 (inclusive), 1938-1962 (bulk). Collection Manuscripts \& Archives. Digital Images Database. New Haven: Yale University. http://images.library.yale.edu/madid/

FletCHer, RaCHel. 2005. Six + One. Nexus Network Journal 7, 1 (Spring 2005): 141-160.

Knight, Richard. 2008. Saarinen's Quest: A Memoir. San Francisco: William Stout Publishers. Merkel, Jayne. 2005. Eero Saarinen. London: Phaidon Press Limited.

Miller, Will. 2006. Eero and Irwin: Praiseworthy Competition with One's Ancestors. Pp. 57-67 in Eero Saarinen: Shaping the Future, Eeva-Liisa Pelkonen and Donald Albrecht, eds. New Haven: Yale University Press. 
OlivareZ, Jennifer Komar. 2006. Churches and Chapels: a New Kind of Worship Space. Pp. 266275 in Eero Saarinen: Shaping the Future, Eeva-Liisa Pelkonen and Donald Albrecht, eds. New Haven: Yale University Press.

PelKonen, Eeva-Liisa and Donald Albrecht, eds. 2006. New Haven: Yale University Press.

RaY, MaIA LeA. 2005. Eero Saarinen: Creating Sacred Space. Master Thesis, University of Louisville.

SaARinen, Aline B. 1962. Eero Saarinen on His Work. New Haven: Yale University Press.

Saarinen's Church. 1964. Architectural Record 136 (September 1964): 185-190.

Thayer, Laura, Louis Joyner and Malcolm Cairns. 1999. "National Historic Landmark Nomination: North Christian Church." United States Department of the Interior, National Park Service. http://www.nps.gov/history/nhl/designations/samples/in/nchrist.pdf

\section{About the author}

Rachel Fletcher is a geometer and teacher of geometry and proportion to design practitioners. With degrees from Hofstra University, SUNY Albany and Humboldt State University, she was the creator/curator of the museum exhibits "Infinite Measure," "Design by Nature" and "Harmony by Design: The Golden Mean" and author of the exhibit catalogs. She is an adjunct professor at the New York School of Interior Design. She is founding director of the Housatonic River Walk in Great Barrington, Massachusetts, co-director of the Upper Housatonic Valley African American Heritage Trail, and a director of Friends of the W. E. B. Du Bois Boyhood Homesite. She has been a contributing editor to the Nexus Network Journal since 2005. 